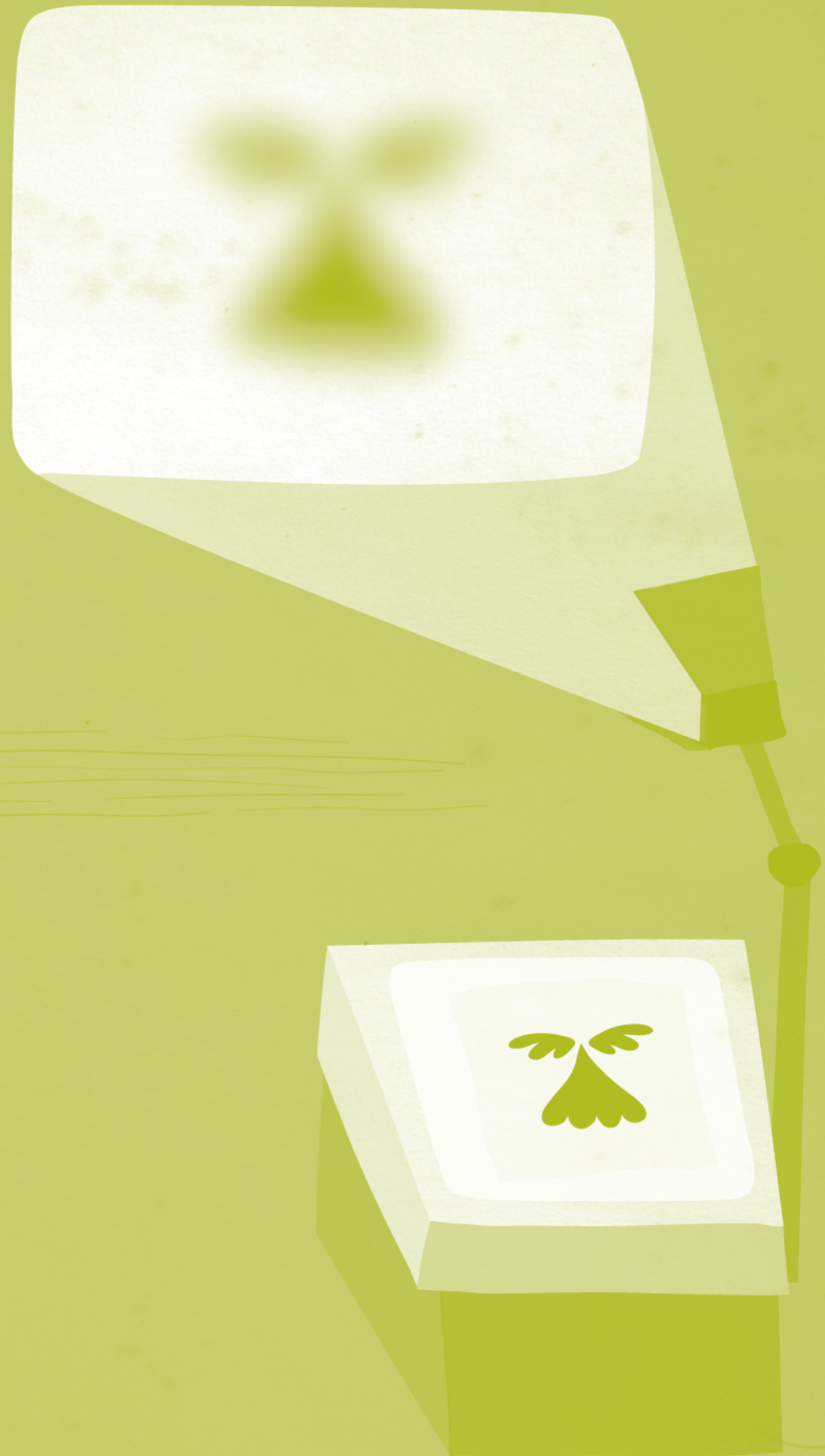




\section{Identidade de marca, gestão e comunicação}

Ruth Peralta Vásquez

- Doutora e Mestre em Ciências da Comunicação pela Escola de Comunicações e Artes da Universidade de São Paulo (ECA-USP)

- Bacharel em Ciências da Comunicação pela Faculdade de Ciências da Comunicação da Universidad de Lima, Peru

- Docente em Comunicações na Pontificia Universidad Católica del Perú (PUCP), Universidad Nacional Mayor de San Marcos (UNMSM), Universidad Femenina del Sagrado Corazón (Unifé) e Universidad de Lima, todas no Peru

- Assessora acadêmica e consultora em gestão de marca

• peruth@yahoo.com 


\section{Resumo}

Este artigo aborda o estudo da marca sob o aspecto da sua identidade. Assim, como a identidade pessoal, a identidade de marca também tem uma série de elementos que a caracterizam, dotando-a de uma personalidade. Apresenta-se o papel que cumpre a identidade de marca, sua comunicação e seu resultado quando transformada em imagem.

PALAVRAS-CHAVE: MARCA • PRODUTO • IDENTIDADE • COMUNICAÇÃO • IMAGEM

\section{Abstract}

This article addresses the study of brands from the aspect of their identities. Thus, not unlike personal identity, a brand identity also carries a series of elements by which it is characterized and that ascribe to it a personality. The article shows the role played by brand identity, its communication and its resulting transformation into image.

KEYWORDS: BRAND • PRODUCT • IDENTITY • COMMUNICATION • IMAGE

\section{Resumen}

Se aborda el estudio de la marca bajo el aspecto de su identidad. Así como la identidad personal, la identidad de marca también posee una serie de elementos que la caracterizan, dotándola de una personalidad. Se presenta el papel que cumple la identidad de marca, su comunicación y su resultado cuando se transforma en imagen.

PALABRAS CLAVE: MARCA • PRODUCTO •IDENTIDAD • COMUNICACIÓN •IMAGEN 
marca, como foco de estudo deste artigo, foi também o assunto principal da minha tese de doutorado defendida em 2006 na Escola de Comunicações e Artes da Universidade de São Paulo (ECA-USP), sob orientação do Prof. Dr. Mitsuru H. Yanaze. A pesquisa realizada teve como objeto de estudo a comunicação da identidade de mar$\mathrm{ca}$, sob o ponto de vista da publicidade impressa. Foram definidas as bases nas quais uma marca é construída e os fatores comunicacionais pelos quais uma marca pode ou não transmitir uma imagem coerente com seus objetivos. A fundamentação teórica levantada embasou a análise do caso escolhido: a campanha de reposicionamento da Avon. A empresa realizou uma série de mudanças na sua comunicação com a finalidade de elevar a imagem da sua marca que vinha sendo percebida inadequadamente: não representava os objetivos nem os princípios da corporação. Deste modo, pode-se comprovar a necessidade constante de vigiar a marca sob todos os pontos de vista, porque nem sempre o volume de vendas representa uma imagem de marca forte ${ }^{1}$.

Este artigo propõe-se a fornecer os conceitos básicos da identidade de marca, sua gestão e sua divulgação. Entende-se como identidade o ponto de partida na criação de uma marca que antecede, inclusive, a existência do produto.

\section{Marca}

As marcas são valiosas para as empresas. Apesar de não serem ativos físicos, fazem parte do patrimônio das corporações. As transações das marcas (vendas, aquisições e fusões) revelam seu valor monetário e, por conseguinte, determinam o quanto elas significam. Em um mercado cada vez mais disputado, faz-se necessário construir uma marca forte, sólida e competitiva que alcance não só os objetivos comerciais, mas, também, que conquiste a mente do consumidor.

Existem muitos estudos a respeito da marca e sua definição é delimitada a uma série de conceitos, principalmente, àquele que a define como um sinal visual que identifica um produto. No entanto, na atualidade, uma marca é identificada não só por meio de uma característica visual (logotipo), como também, por outras que estão implícitas. "A IBM não vende computadores, mas soluções para os negócios. A Swatch não tem relação com relógios, mas com o conceito de tempo" (KLEIN, 2002, p. 48). Deste

1 A tese de doutorado citada é parte do acervo da biblioteca da ECA-USP, sob o título Comunicação de marca: aportes da publicidade impressa na comunicação da identidade de marca. 
modo, o consumidor vincula uma marca não só com uma qualidade física do produto, mas com uma série de associações emocionais e sociais que ela transmite: tomase uma Coca-Cola e não uma Pepsi, compra-se leite Nestlé e não Parmalat, ou viceversa. Assim, é definida uma marca, um conceito, uma atitude, uma postura e um conjunto de valores que vão além dos atributos do produto. Portanto, a marca reúne uma série de conceitos que Kapferer (1998, p. 190) resume da melhor forma:

"Uma marca é ao mesmo tempo signo, palavra, objeto, conceito. Signo, pois a marca é multiforme: ela integra os signos figurativos, como os logotipos, os emblemas, as cores, as formas, as embalagens e o design. Palavra, no caso o nome da marca, que é o suporte de informação oral ou escrita sobre o produto. Objeto, pois a marca distingue um ou vários produtos de outros produtos ou serviços. Conceito, enfim, pois a marca, como todo signo, tem um significado, ou seja, um sentido."

\section{Identidade de marca}

Existem duas explicações de por que o consumidor usa uma determinada marca. A primeira, porque ela lhe transmite certas sensações e ele se identifica com elas. A segunda, porque ela representa algo que ele aspira ter em termos de imagem, algo que ele não tem e que a marca pode lhe proporcionar. A marca não é só um logotipo, uma etiqueta ou um slogan; a verdadeira essência radica em seu significado, um meio de vida, uma atitude, um conjunto de valores, uma expressão, um conceito. "As corporações podem fabricar produtos, mas o que os consumidores compram são marcas" (KLEIN, 2002, p. 31).

A identidade é o suporte pelo qual se constrói a marca. É ela que dá uma direção, um propósito e um significado à marca: norteia as ações empresariais e financeiras, define os objetivos mercadológicos e comunicacionais e transmite, por meio de seus símbolos, um sentido, um conceito.

A identidade de marca deve reunir certos princípios para que cumpra seus propósitos. Ela tem de ser:

Única e intransferível. Toda identidade pertence a uma marca específica. Não existem duas marcas com a mesma identidade. Um produto pode ser copiado, mas é muito difícil copiar sua identidade.

Atemporal e constante. A identidade não tem tempo nem limite de validade. No entanto, ela deve ser constante no tempo. Marlboro sempre representou individualidade, força e masculinidade por meio do personagem do caubói.

Consistente e coerente. A identidade deve ser sólida em seus elementos constitutivos, ao mesmo tempo em que deve existir correlação entre eles, sendo congruentes e compatíveis entre si.

Objetiva e adaptável. A identidade deve ser direta em seus propósitos e sua comunicação adaptada de acordo com seu público-alvo. 
A identidade de marca abrange duas áreas, uma externa e outra interna. A externa define a marca por seu aspecto físico. Hoje em dia, é impossível pensar um produto sem um nome e um logotipo que o distinga. Para cada produto ou empresa corresponde uma marca, e com ela características visuais específicas. Essas características fazem parte da identidade visual da marca que, tal como a ponta do iceberg, representa o que está na superfície, o que está visível. A parte submersa do iceberg representa a área interna, chamada de identidade conceitual da marca. É ela que vai definir a razão de ser da empresa e de seus produtos: quem são e aonde querem chegar. A identidade visual é a materialização da identidade conceitual. Identifica a empresa e seus produtos externamente por meio da concepção, desenvolvimento e operacionalização dos elementos gráficos (logotipo, rótulo, papelaria e afins).

A identidade de marca divide-se em dois aspectos: a identidade de marca da empresa e a identidade de marca do produto. Em cada um deles, tanto os elementos internos (identidade conceitual) como externos (identidade visual) devem atuar em conjunto na construção de uma imagem sólida e unificada. Deste modo, a identidade de marca, tanto da empresa como do produto, baseia-se neste relacionamento conceitual-visual.

\section{Figura 1}

\section{Estrutura da identidade de marca}

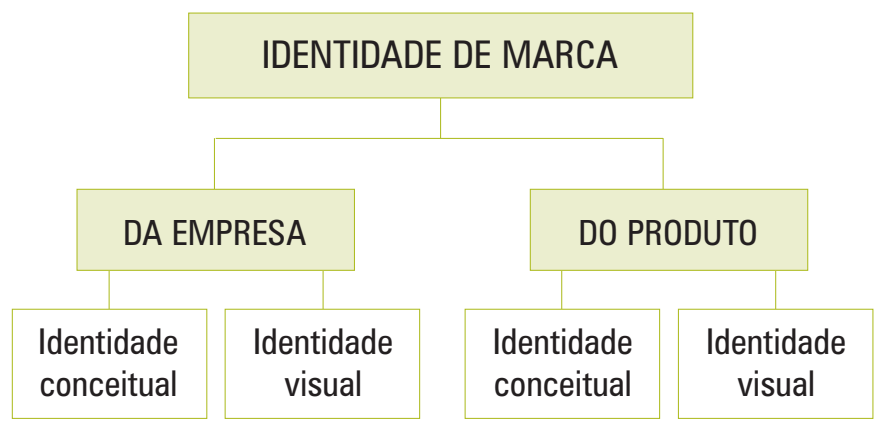

A identidade de marca de uma empresa envolve sua relação com seus públicos, sejam estes internos ou externos à organização, abrangendo áreas diversas como a financeira, institucional, social, política, entre outras. No caso do produto, sua ação é focalizada, principalmente, nos consumidores - seu público direto -, embora também participe com os demais públicos da área comercial (distribuidores, vendedores etc.).

A identidade conceitual da empresa, também chamada de identidade conceitual corporativa, é o suporte que sustenta a identidade conceitual do produto. A marca incorpora um significado ao produto definido por meio dos elementos tangíveis (atributos, características e funções) e intangíveis (benefícios que os consumidores concedem 
aos produtos). No entanto, como todo produto é gerado dentro da empresa, ele tem como base os objetivos organizacionais, as diretrizes, os princípios e os valores sobre os quais a marca corporativa é construída.

\section{Identidade conceitual}

A identidade conceitual da empresa ou corporativa é o conjunto de características internas que permitem identificar e diferenciar uma empresa de outra. Ela é definida com base na missão, na visão e na cultura corporativa. A missão é o ponto de partida das ações da empresa, é o propósito que justifica a sua existência; define o tipo de atividade que ela vai desenvolver. A visão, por sua vez, é aspiracional. Sua definição marca o rumo, o tipo de atividade na qual a empresa vai atuar e os objetivos que ela quer alcançar. Seu enunciado deve ser direto e enfático. Assim, a visão da Nike é definida como: a melhor empresa de esporte e forma fisica do mundo. Seu CEO, Phil Knight, a define como "uma empresa de esportes; sua missão não é vender calçados, mas melhorar a vida das pessoas pela prática de esportes e a forma física, e manter viva a magia dos esportes" (KLEIN, 2002, p. 47).

A cultura corporativa é entendida como o conjunto de símbolos, padrões e códigos que se cria, se preserva ou aprimora ao longo do tempo e que é compartilhado por um grupo de pessoas reunido para um fim comum, sujeito a regras ou estatutos e com direitos e deveres a cumprir. Assim, a cultura corporativa é produto da experiência compartilhada pelos integrantes da organização e manifestada por meio de quatro elementos: valores, símbolos, ritos e heróis. Neles se assentam as bases da identidade conceitual que é única e pertence a apenas uma empresa. Pode até ser fácil imitar um produto, mas muito difícil duplicar uma companhia. Os valores corporativos são a sustentação intangível dos produtos, que são o sustento material da empresa e o suporte físico no qual se alicerça a marca.

Uma empresa pode atribuir a seus produtos e serviços uma série de características como pontos de diferenciação. Os elementos da identidade conceitual que fazem parte do produto (em alguns casos podem ser adaptados aos serviços) são: as variáveis do produto (características físicas), as variáveis dos serviços (como ações complementares no oferecimento dos produtos) e as variáveis do pessoal (características e funções dos funcionários da empresa). Os três componentes devem refletir uma imagem coerente com a identidade de marca da empresa.

Assim como existem produtos que foram se modificando com o passar dos anos (mudança de embalagem, diversificação do produto etc.), também há marcas que foram evoluindo e se atualizando (modernização do logotipo, atualização das mensagens publicitárias etc.), conservando intacta sua essência, como é o caso da Coca-Cola, com 119 anos de existência. Tanto a marca corporativa como a do produto, ligadas aos valores norte- 
Figura 2

Elementos da cultura corporativa

\begin{tabular}{|c|c|c|c|}
\hline & \multicolumn{2}{|c|}{ CULTURA CORPORATIVA } & \\
\hline VALORES & síMBOLOS & RITOS & HERÓIS \\
\hline $\begin{array}{l}\text { Padrões sociais } \\
\text { implementados pela } \\
\text { empresa e aceitos } \\
\text { pelos integrantes da } \\
\text { organização em } \\
\text { todos os níveis. }\end{array}$ & $\begin{array}{l}\text { Elementos que se } \\
\text { associam com a } \\
\text { marca: um } \\
\text { personagem, um } \\
\text { mascote, uma cor, } \\
\text { uma embalagem, um } \\
\text { logotipo, o próprio } \\
\text { produto etc. }\end{array}$ & $\begin{array}{l}\text { Atividades para a } \\
\text { integração dos } \\
\text { membros da } \\
\text { companhia. Nelas } \\
\text { reforçam-se, } \\
\text { modificam-se e } \\
\text { incorporam-se novas } \\
\text { atitudes, vínculos e } \\
\text { comportamentos. }\end{array}$ & $\begin{array}{l}\text { Pessoas (vivas ou } \\
\text { falecidas) } \\
\text { reconhecidas por } \\
\text { todos e que servem } \\
\text { como modelos de } \\
\text { comportamento aos } \\
\text { membros da } \\
\text { corporação. }\end{array}$ \\
\hline $\begin{array}{c}\text { São a base da } \\
\text { cultura } \\
\text { corporativa }\end{array}$ & $\begin{array}{c}\text { Trazem } \\
\text { significados à } \\
\text { empresa }\end{array}$ & $\begin{array}{l}\text { Expressam a } \\
\text { cultura } \\
\text { corporativa }\end{array}$ & $\begin{array}{l}\text { Proporcionam } \\
\text { modelos de } \\
\text { conduta }\end{array}$ \\
\hline
\end{tabular}

Figura 3

\section{Elementos da identidade conceitual do produto}

\begin{tabular}{|c|c|c|}
\hline PRODUTO & SERVIÇOS & PESSOAL \\
\hline COMPONENTES & PRÉ-VENDA & CARACTERÍSTICAS \\
\hline $\begin{array}{l}\text { Características } \\
\text { Desempenho }\end{array}$ & $\begin{array}{l}\text { Demonstração } \\
\text { Simulação }\end{array}$ & \multirow{5}{*}{$\begin{array}{l}\text { Competência } \\
\text { Cortesia } \\
\text { Credibilidade } \\
\text { Confiabilidade } \\
\text { Capacidade de resposta } \\
\text { Comunicação }\end{array}$} \\
\hline APRESENTAÇÃOO & VENDA & \\
\hline $\begin{array}{l}\text { Forma } \\
\text { Estilo } \\
\text { Design }\end{array}$ & $\begin{array}{l}\text { Pedido } \\
\text { Entrega } \\
\text { Instalação }\end{array}$ & \\
\hline USO & PÓS-VENDA & \\
\hline $\begin{array}{l}\text { Durabilidade } \\
\text { Conformidade } \\
\text { Confiabilidade } \\
\text { Facilidade de reparo }\end{array}$ & $\begin{array}{l}\text { Treinamento do cliente } \\
\text { Orientação ao cliente } \\
\text { Manutenção e reparo } \\
\text { Serviços diversos }\end{array}$ & \\
\hline
\end{tabular}

Adaptado de Kotler (2000, p. 310)

americanos, foram e continuam sendo construídas e dotadas de uma sólida identidade. Como prova de sua fortaleza, está a rejeição, por parte de seus consumidores, à New Coke, em 1985. A modificação da fórmula de seu refrigerante, como uma medida estratégica para se defender dos avanços perigosos da Pepsi, teve dois significados antagônicos: por um lado, o fracasso na introdução do produto e, por outro, o reconhecimento e a fidelidade que o consumidor professava à Coca-Cola clássica. A New Coke 
trouxe a idéia de uma cópia malfeita da original. A marca estava identificada com um determinado sabor e substituí-lo era impossível. Isso demonstrou a forte identidade que a marca havia construído ao longo dos anos quanto aos atributos físicos (cor e gosto), visuais (rótulo e embalagem) e simbólicos (valores nacionais). Deste modo, produto e marca atuam em conjunto: a identidade do produto se delimita pelo seu aspecto material, e a marca proporciona o aspecto imaterial, outorgando-lhe um significado.

\section{Identidade visual}

A identidade visual é um sistema de signos criado, organizado e disposto segundo critérios e princípios que visam representar, caracterizar e comunicar a identidade conceitual da marca. Sua sistematização e delimitação respondem a um programa controlado pela empresa.

Pela identidade visual, o invisível torna-se visível. Com a criação de um nome e a incorporação de um design se materializa a identidade conceitual. Por meio dos elementos visuais outorga-se uma personalidade à marca, fazendo com que ela se diferencie das outras. Deste modo, a identidade visual é um sistema que proporciona unidade e identidade a uma empresa, a um grupo ou uma instituição, bem como a seus produtos ou serviços.

A identidade visual reúne as seguintes funções:

Identifica. Ela permite identificar um produto ou serviço. A atração visual que os elementos gráficos exercem (como a concha da Shell, por exemplo) gera associações entre a marca e o consumidor.

Diferencia. Dotar uma marca de elementos gráficos únicos possibilita a diferenciação da concorrência. Numa prateleira cheia de produtos de diferentes marcas, a cor (por exemplo) é um recurso que permite localizar, com maior facilidade, uma marca.

Associa. A identidade visual funciona como um carimbo. O logotipo no uniforme e na papelaria como nos carros de entrega e nas embalagens, vincula o produto e, às vezes, também, a empresa ou o fabricante com o consumidor.

Reforça. A identidade visual reforça a imagem da empresa. Acrescenta associações favoráveis e consolida sua posição perante a concorrência. Por exemplo, a letra digitalizada "X", da Xerox, representa a incorporação da companhia à era digital.

O grau de reconhecimento da marca vai depender da forma como a identidade conceitual foi concretizada por meio do aspecto visual. A identidade visual deve seguir os seguintes princípios: ser única (o fruto do guaraná com o nome do refrigerante no logotipo), autêntica (as três listras do logotipo da Adidas), original (a maçã como símbolo dos computadores Apple), criativa (o raio do Gatorade reforça o atributo do produto: bebida que repõe as energias), consistente (o ninho da Nestlé), clara (o logotipo do 
OMO é simples e permite a sua identificação a distância), coerente (o uso da pomba da Dove em produtos que tem a ver com suavidade, como sabonete, cremes corporais, desodorantes etc.), adaptável (o nome Coca-Cola traduzido em diferentes idiomas), viável (possibilidade de ser reproduzida em diferentes suportes e materiais) e susceptível a proteção. Com base nesses princípios, os elementos da identidade visual da marca devem ser planejados, implementados e controlados para tornarem-se eficazes.

É pela identidade visual que o público identifica e reconhece uma marca. No entanto, sua finalidade difere um pouco entre a empresa e o produto. No caso da empresa, o objetivo é representá-la como uma organização; no caso dos produtos, o propósito é dotá-los de uma identidade externa individualizada. A divulgação desta última se aplicará em suportes que visam à comunicação mercadológica dirigida principalmente ao consumidor.

\section{Comunicação da identidade}

A comunicação é um diálogo entre dois agentes: num extremo, a fonte geradora das mensagens e, no outro, a fonte receptora dessas mensagens. A comunicação faz parte de um processo por meio do qual a informação é transmitida de um emissor (próximo ou remoto) a um receptor (individual ou coletivo). O fluxo da comunicação decorre por meio da retroalimentação, ou feedback, entre o emissor e o receptor, neste caso, entre a empresa e o consumidor.

A identidade de marca é a base na qual se sustenta toda a comunicação. A finalidade da comunicação é construir uma imagem relativa a essa identidade. Portanto, a comunicação intervém como mecanismo transmissor que atua como elemento transformador ou codificador da identidade em mensagem, e como criadora das condições necessárias para a sua distribuição aos públicos-alvo (TAJADA, 1994, p. 137).

\section{Figura 4}

\section{Elementos da identidade visual e sua aplicação}

\begin{tabular}{|c|c|c|}
\hline $\begin{array}{c}\text { IDENTIDADE } \\
\text { VISUAL DA MARCA }\end{array}$ & ELEMENTOS & APLICAÇÃO \\
\hline CORPORATIVA & $\begin{array}{l}\text { Logotipo } \\
\text { Personagem }\end{array}$ & $\begin{array}{l}\text { Campanhas publicitárias institucionais } \\
\text { Papelaria: impressos em geral } \\
\text { Sinalização: interna e externa, mobiliário etc. } \\
\text { Transporte e vestuário }\end{array}$ \\
\hline DO PRODUTO & $\begin{array}{l}\text { Logotipo } \\
\text { Personagem } \\
\text { Rótulo } \\
\text { Embalagem }\end{array}$ & $\begin{array}{l}\text { Campanhas publicitárias } \\
\text { Promoção de venda: displays, brindes etc. } \\
\text { Merchandising } \\
\text { Mala direta, cartas, catálogos, folhetos etc. } \\
\text { Transporte e vestuário }\end{array}$ \\
\hline
\end{tabular}


Aos dois tipos de identidade de marca - a corporativa e a de produto - correspondem também dois tipos de comunicação: a Comunicação Corporativa, também chamada Institucional, e a Comunicação Comercial ou de Produto. A primeira tem foco na comunicação vinculada aos aspectos corporativos e na difusão do portfólio da empresa. E a segunda, direcionada, basicamente, à conquista do consumidor traduzida na aquisição do produto.

Tanto a Comunicação Corporativa como a Comercial utilizam programas de comunicação para a divulgação da informação, alguns compartilhados por ambas, como Relações Públicas e Publicidade. Esse conjunto de programas é chamado de Comunicação Integrada de Marketing (CIM) que, por sua vez, faz parte do mix de marketing juntamente com o produto, o preço e a praça (ou distribuição).

As ferramentas de comunicação utilizadas numa campanha devem estar integradas para que a mensagem a ser comunicada tenha um único significado. A CIM atende justamente a esta sinergia: todos os programas de comunicação (publicidade, promoções, vendas diretas etc.) devem transmitir um único conceito ou comunicar uma única mensagem com uma única linguagem. Cada vez que o consumidor estiver exposto à marca, seja qual for o veículo usado, deverá percebê-la com um único significado. A sinergia no mix de comunicação traz como conseqüência coerência na mensagem e pode produzir impacto nas vendas; relaciona a imagem de marca da empresa com seus produtos; cria uma imagem de marca forte e unificada; integra as diferentes ati-

\section{Figura 5}

\section{Comunicação da identidade de marca}

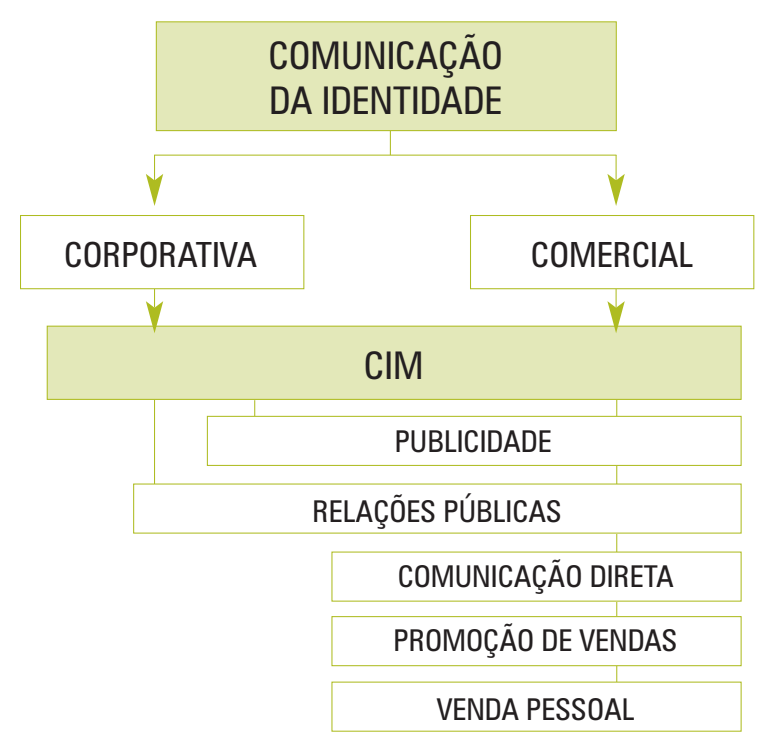


vidades da empresa (corporativa e comercial) entre si e com o consumidor. Quando transmitida ao público certo, no momento oportuno, a mensagem otimiza recursos e melhora a capacidade da empresa de atingir seus objetivos.

A CIM utiliza diversas ferramentas de comunicação que incluem, além dos meios tradicionais (televisão, radio, jornal etc.), uma lista muito ampla de mídia alternativa, como placas de rua, merchandising nas novelas, cartazes em bares, anúncios no interior de táxis etc. A versatilidade dos meios possibilita não só atingir diferentes tipos de consumidores, mas também a redução dos custos. Assim, meios não tradicionais são formas de contato potencialmente importantes e que podem ser financeiramente mais acessíveis.

A seleção dos programas de comunicação varia de acordo com o tipo de público que se quer atingir (consumidores, fornecedores, distribuidores etc.) e de acordo com a forma de comunicação (corporativa ou comercial) que se quer transmitir. O objetivo da CIM é atingir o público-alvo de várias formas e com diversos recursos, ou com base em vários flancos.

\section{Identidade e imagem}

A relação trilógica identidade-comunicação-imagem fica evidenciada na compatibilidade dos três elementos e no efeito que surge na percepção da marca. A identidade diz respeito ao ser da empresa; a imagem, ao parecer. A identidade está relacionada com a maneira como uma empresa visa identificar e posicionar a si mesma e seus produtos. Entretanto, a imagem é a maneira como o público vê a empresa e seus produtos (KOTLER, 2000, p. 318).

A relação entre identidade e imagem é uma relação causa-efeito na qual a causa é a identidade a ser comunicada, e o efeito é a percepção dessa identidade projetada em imagem (TAJADA, 1994, p. 143). A identidade é a concepção que a marca tem de si mesma; a imagem é a maneira pela qual o público concebe a marca. A identidade se constrói internamente; a imagem, externamente. A identidade é objetiva; a imagem é subjetiva e simbólica. A imagem se configura com base na identidade; a identidade precede a imagem. A identidade e a imagem de marca diferem em forma e conteúdo, porém, o vínculo entre elas é a comunicação.

Toda imagem é conseqüência da comunicação. Portanto, do processo de comunicação se produzem duas possibilidades: a imagem de marca coincide com sua identidade (comunicação ideal) ou não (comunicação distorcida).

Na comunicação ideal, a transmissão da identidade de marca corporativa ou de produto (conceitual e visual) é adequada. A identidade definida e materializada corretamente por meio das ferramentas de comunicação produz sua imagem correspondente. Se a Volvo criou uma imagem de segurança, ela se deve em parte aos atributos identificados graças à tecnologia usada na fabricação de seus autos. 
Uma boa imagem se converte em um fator decisivo para a escolha da marca: o consumidor satisfaz suas necessidades racionalmente por meio dos atributos do produto, e emocionalmente pela percepção da marca do produto. Uma fábrica produz perfume, mas uma pessoa compra sensações; usar uma determinada marca significa que ela poderá se sentir mais romântica, elegante ou sensual. "Ao estabelecer a marca um elo com o consumidor, que vai muito além da qualidade do produto, a imagem, se converte em um fator decisivo para a escolha da mesma" (MARTINS, 1999, p. 17).

No caso da comunicação distorcida, produz-se um lapso entre a identidade e a imagem de marca, corporativa ou de produto, que pode ser entendido de duas maneiras. $\mathrm{Na}$ primeira, a identidade de marca não é bem definida, mas a imagem formada é forte e consistente. Quando a publicidade enaltece uma identidade fraca, está disfarçando a verdadeira identidade. O problema está na definição da identidade de marca do produto ou da empresa, seja na parte conceitual ou visual. Para que a marca seja comunicada da melhor maneira, é conveniente que a identidade de marca seja forte, memorável, focalizada e motivadora (AAKER; JOACHIMSTHALER, 2001, p. 111). Quando os elementos constitutivos da identidade não são consistentes nem coesos, a imagem positiva formada não dura muito tempo. A falta de credibilidade é o principal problema que surge desse tipo de comunicação: propor ao consumidor algo que a marca não pode cumprir cria um desgaste na imagem de marca.

No segundo caso, a marca tem uma identidade bem definida e forte, mas não sabe comunicá-la, transmitindo uma identidade diminuída e fraca. Nesse caso, o problema está na comunicação: na má conceitualização, na falta de criatividade ou na incorre-

\section{Figura 6}

Tipos de comunicação de marca

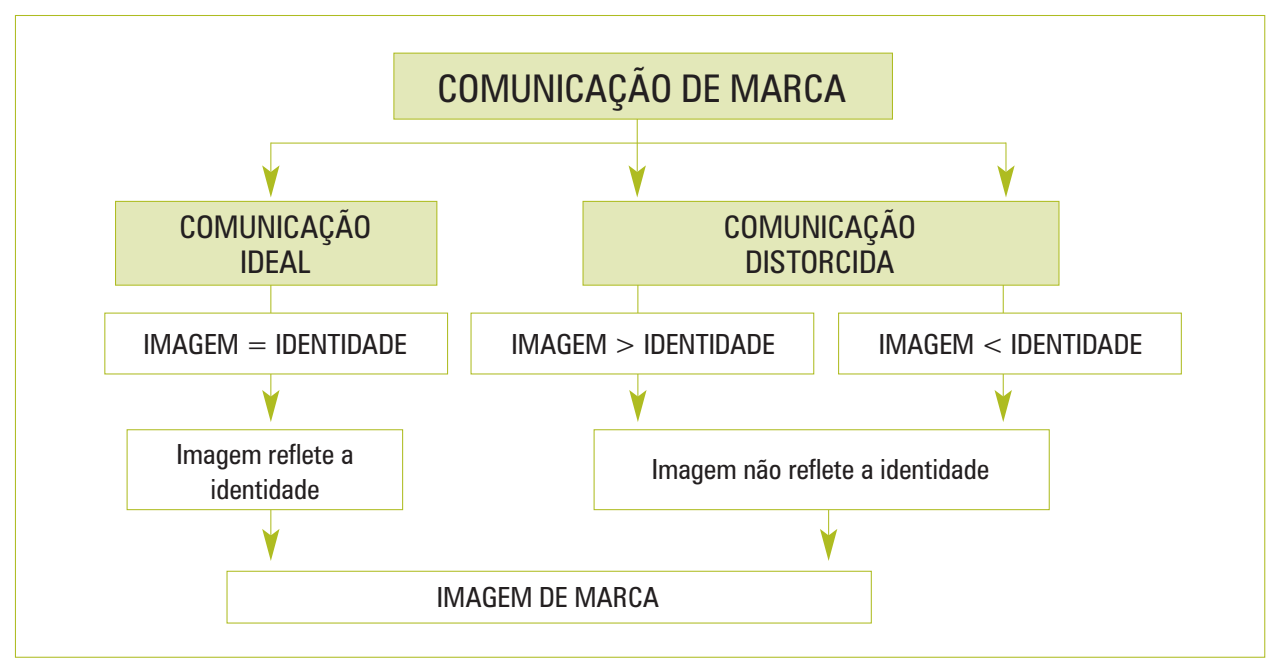


ta realização final. Deste modo, a marca pode chegar a ser percebida sem vigor nem vitalidade e influir na percepção dos outros produtos da empresa. A falta de atualização nas comunicações resulta numa imagem de marca envelhecida e enfraquecida, e pode conduzir ao declínio e ao desaparecimento do produto.

Uma imagem negativa prejudica a reputação da empresa. Uma crise de imagem, antes de tudo, é uma crise de confiança, de credibilidade, de reputação. O que uma empresa vende não é um produto, mas uma marca, e com ela uma série de associações. Sendo assim, o McDonald's não vende ou produz sanduíches. O que ele realmente vende é a confiança traduzida na qualidade dos produtos, na segurança das instalações, nos serviços oferecidos, assim como nos símbolos que ele utiliza, como o personagem Ronald McDonald vinculado a ações humanitárias, sociais e de entretenimento. Portanto, quando a marca é devidamente gerada e comunicada, traz retorno econômico e financeiro para a empresa, e ajuda a superar, minimizar e, às vezes, a prevenir crise de imagem. Afinal, é o consumidor o fiscal desse processo.

\section{Referências}

AAKER, David. El éxito de tu produto está en la marca. México: Prentice Hall Hispanoamericana S.A., 1996. ; JOACHIMSTHALER, Erich. Liderazgo de marca. Bilbao: Ed. Deusto S.A., 2001.

KAPFERER, Jean-No_I. As marcas: capital da empresa. São Paulo: Bookman, 1998.

KELLER, Kevin L. Gestão estratégica de marcas. São Paulo: Prentice Hall, 2005.

KLEIN, Naomi. Sem logo. Rio de Janeiro: Record, 2002.

KOTLER, Philip. Administração de marketing. São Paulo: Prentice Hall, 2000.

KUNSCH, Margarida K. Planejamento de relações públicas na comunicação integrada. São Paulo: Summus, 2003.

MARTINS, José. A natureza emocional da marca. São Paulo: Negócios, 1999.

PEREZ, Clotilde. Signos da marca: expressividade e sensorialidade. São Paulo: Thomson, 2004.

PINH0, José Benedito. 0 poder das marcas. São Paulo: Summus, 1996.

REG0, Francisco Gaudêncio Torquato do. Comunicação empresarial/comunicação institucional. São Paulo: Summus, 1986.

SHULTZ, Don E. Campanhas estratégicas de comunicação de marca. Rio de Janeiro: Qualitymark, 2001.

TAJADA, Luis Ángel Sanz de la. Integración de la identidad y la imagen de la empresa. Madrid: ESIC, 1994.

TAVARES, Mauro Calixta. A forca da marca. São Paulo: Harbra, 1998.

VILLAFAÑE, Justo. Imagen positiva. Madrid: Pirámide, 1998.

YANAZE, Mitsuru H. Gestão de marketing e comunicação: avanços e aplicações. São Paulo: Saraiva, 2007. 